\title{
Evaluation of Strain Measurement Devices for Inflatable Structures
}

\author{
Douglas A. Litteken ${ }^{1}$ \\ NASA Johnson Space Center (JSC), Houston, TX, 77058
}

\begin{abstract}
Inflatable structures provide a significant volume savings for future NASA deep space missions. The complexity of these structures, however, provides difficulty for engineers in designing, analyzing, and testing. Common strain measurement systems for metallic parts cannot be used directly on fabrics. New technologies must be developed and tested to accuractly measure the strain of inflatable structures. This paper documents the testing of six candidate strain measurement devices for use on fabrics. The resistance devices tested showed significant hysteresis during creep and cyclic testing. The capacitive device, however, showed excellent results and little-to-no hysteresis. Because of this issue, only two out of the six proposed devices will continue in development. The resulting data and lessons learned from this effort provides direction for continued work to produce a structural health monitoring system for inflatable habitats.
\end{abstract}

$\begin{array}{ll}\text { BEAM } & =\text { Bigelow Expandable Activity Module } \\ \text { HIAD } & =\text { Hypersonic Inflatable Aerodynamic Decelerator } \\ \text { in } & =\text { inches } \\ \text { ISS } & =\text { International Space Station } \\ M M O D & =\text { micro-meteorioid and orbital debris } \\ p F & =\text { picofarad } \\ \text { RTV } & =\text { Room Temperature Vulcanization } \\ \text { SHM } & =\text { Structural Health Monitoring } \\ V & =\text { voltage } \\ \% & =\text { percent }\end{array}$

\section{Introduction}

$\mathrm{O}$ ne of the biggest challenges facing NASA's deep space exploration goals is structural mass. A long duration transit vehicle on a journey to Mars, for example, requires a large internal volume for cargo, supplies and crew support. As with all space structures, a large pressure vessel is not enough. The vehicle also requires thermal insulation, micro-meteoroid and radiation protection, a navigation and control system, a propulsion system, a power system and a life support system. As vehicles get larger, their associated systems also get larger and more complex. These vehicles require larger lift capacities and force the mission to become extremely costly. In order to build large volume habitable space vehicles, with only minimal increases in launch volume and mass, NASA is developing lightweight habitable module structures.

Lightweight structures are made from non-metallic materials including graphite composites and high-strength fabrics and could provide similar or better structural capability than metals, but with significant launch volume and mass savings. Fabric structures specifically have been worked by NASA off-and-on since its inception, but most notably in the 1990's with the TransHAB ${ }^{1}$ program. TransHAB, shown in Figure 1, was a human-rated inflatable habitat intended for

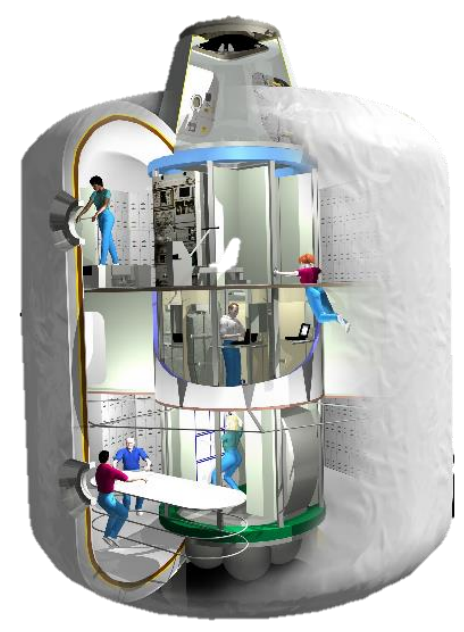

Figure 1. TransHab concept. ${ }^{1}$

\footnotetext{
${ }^{1}$ Structural Engineer, Structural Engineering Division, douglas.litteken@ nasa.gov, AIAA Member 


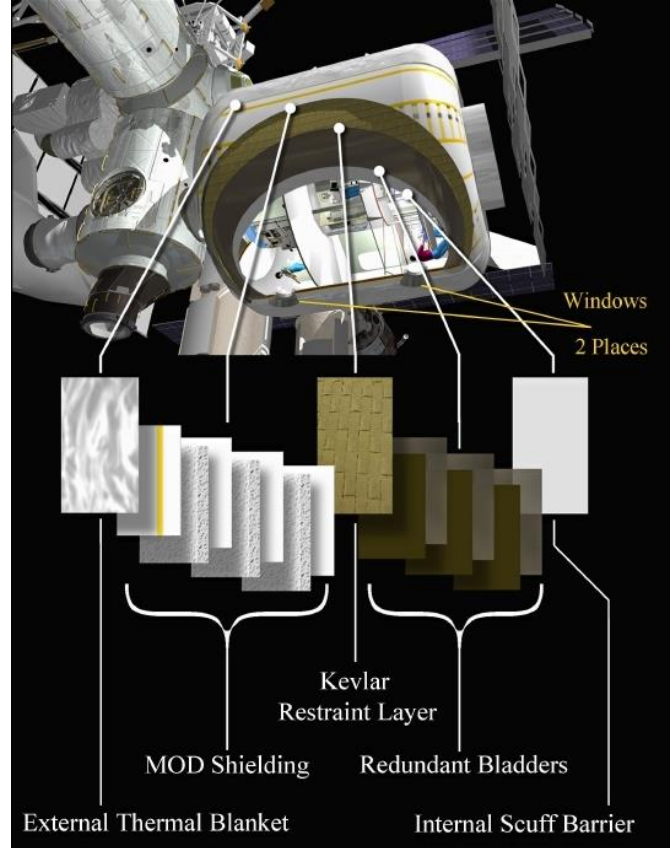

Figure 2. TransHAB shell layers. ${ }^{1}$ long duration transit missions. TransHAB developed a fabric-based inflatable structure that utlized a layered material approach to form a pressure vessel with integrated thermal and micrometoroid debris protection, as shown in Figure 2. The flexible fabrics allow the vessel to be packed in a small volume during launch and expand into a much larger volume with pressurized air once in orbit. NASA and Bigelow Aerospace recently installed the first human-rated inflatable module on the ISS, known as the BEAM ${ }^{2}$ in May of 2016. The module is considered a science payload and is being used for a two-year experiment on the ISS to evaluate the performance of inflatable structures in low Earth orbit.

As lightweight structures are developed, testing methods are vital to understanding their behavior and validating analytical models. Common techniques can be applied to fabric materials, such as tensile testing, fatigue testing, and shear testing, but common measurement techniques cannot be used on fabric. Measuring strain in a material during a pressure test is a critical parameter for engineers to monitor the structure during the test and correlate to an analytical model. The ability to measure strain in inflatable structures is a challenge for NASA. Foil strain gages, for example, are commonplace on metallic structures testing, but are extremely difficult to interface with a fabric substrate. New strain measuring techniques need to be developed for use with fabric structures. This paper investigates options for measuring strain in inflatable structures for both ground testing and inspace structural health monitoring. It evaluates current commercially available options and outlines development work underway to build a SHM solution for NASA's inflatable structures.

\section{Current State of the Art}

NASA's inflatable structures are used as pressure vessels made from a layered composition of high-strength materials as shown in Figure 2. The two primary layers of all fabric pressure vessels are the bladder layer, which holds the internal air and pressure, and the restraint layer, which is the structural layer that takes the loads from the internal pressure and any attached systems. The restraint layer is the most important from a structures standpoint and is the critical loading path where strain is measured. Depending on the vehicle geometry and mission, the restraint layer is composed of a single broadcloth, a weave of flat straps, a pattern of cylindrical cordage, or a combination of two or all three. The broadcloth configuration is typically made of a woven fabric that carries load in multiple directions, much like an orthotropic composite layup. The flat strap and cylindrical cordage, however, carry load uniaxially through the length of the material. TransHAB based inflatable designs utilize a series of inter-woven flat straps in a basket-weave to form the restraint layer ${ }^{1}$. The focus of this strain measuring development effort then, will be on measuring strain in a flat substrate, such as a strap or broadcloth.

Current ground testing of NASA's inflatable structures use non-contact videography systems, known as photogrammetry $^{3}$, to measure strain and deflection of the fabric surfaces. This technique produces very accurate results and very high resolutions. This method has been used on both a flat strap surface and a broadcloth surface with good results. The technique is very dependent on lighting conditions and works well in a controlled test setting, but is difficult to complete outdoors with sun movements throughout the day. Photogrammetry is also challenging to use on a large-scale pressure vessel. The resolution of the camera system is fixed, so moving the camera closer or father from the test article will result in a change in resolution of strain data. For a large test article, then, multiple photo systems are necessary to fully encompass the structure. While this system does work well

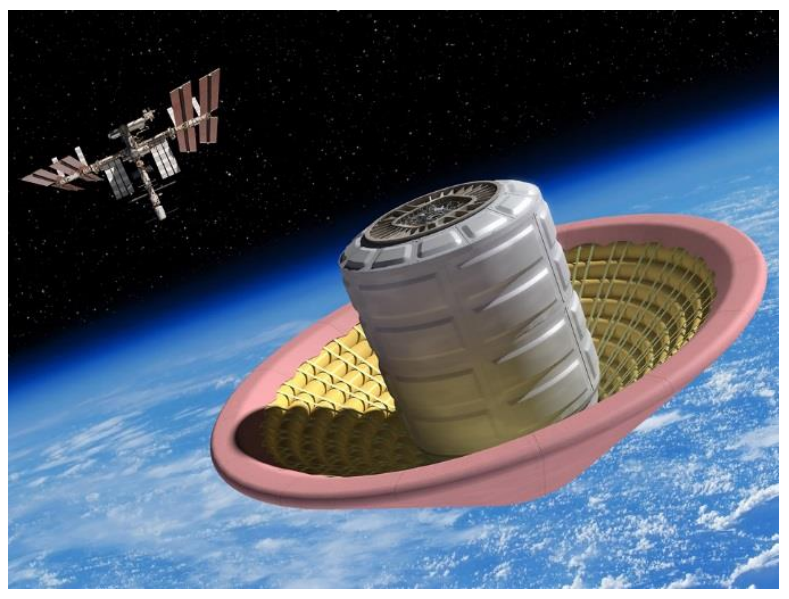

Figure 3. HIAD concept image. ${ }^{4}$ 
on the ground, it cannot be used effectively in space without additional hardware to hold and fix multiple camera locations. Alternate methods that are embedded or integrated into the structure are preferred for on-orbit strain measuring systems.

A similar fabric structure in current development is the NASA HIAD. HIAD is made of concentric inflatable tubes that form an expandable heat shield intended for Mars deceleration. It is made of similar high-strength materials as the habitable pressure vessels explained above, with both broadcloth and flat straps making up the structural components. The HIAD team has tested the system in ground testing and high altitude deployment testing. In order to measure the strain and load in the fabric components, they have used a series of devices, including a high elongation foil strain gage ${ }^{4}$. The foil gages are adhered directly to an epoxy resin substrate that is first

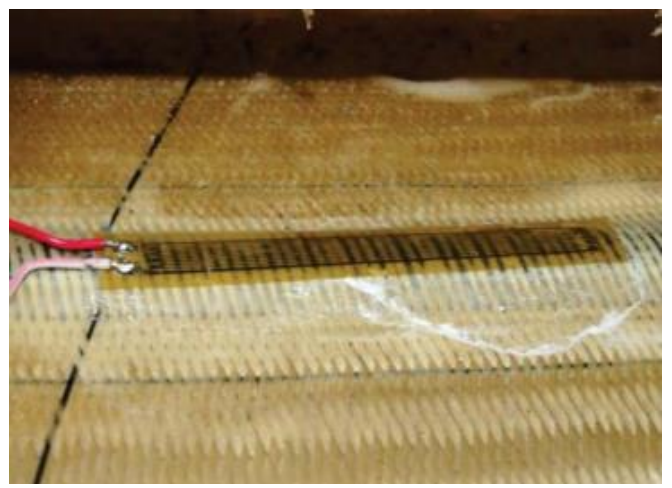

Figure 4. Strain gage on HIAD torus cord. ${ }^{4}$

installed on the broadcloth fabric. The epoxy forms a composite with the broadcloth and creates a surface for the strain gage to be bonded. The gages are then bonded to the composite surface, as shown in Figure 4 and are connected to a data acquisition system. These foil strain gages provided accurate and reliable structural data in both ground and flight testing.

\section{Gage Requirements}

Fabric materials are very flexible and have higher moduli of elasticity than metals. They produce high-elongation strains that can range between 5-50\%, depending on their material stiffness and the applied load. A strain gage for a fabric needs to be in intimate contact with the material and have a greater elasticity than the substrate so that strain can be transferred to the measuring device without any stiffening effects from the device onto the substrate material. It should be integrated on a material or sub-component level to minimize any snagging hazards or interference with other components. The device also needs to withstand the same folding and packing conditions that the fabric structure will see prior to launch and deployment. The deployment phase is a dynamic event and will induce strains on the fabric that need to be captured. The strain measuring device, then, needs to be able to withstand and measure peak dynamic loads. Once deployed, the strain gage will be measuring material strain for the remainder of its life. To be used as a structural health monitoring system, it should be capable of measuring a constant strain over an extended period of time, potentially years, without any loss of signal or resolution.

\section{Gage Descriptions}

The most common type of device for strain measurement is based on a change in resistive properties. A conductive material has a known resistance in its free state and that resistance changes when the material is stretched. Applying an input excitation voltage into the resistor, we can measure the output voltage and correlate the change in resistance to a change in length and thus a strain. A Wheatstone bridge is also used to clean and amplify the results. A typical foil strain gage operates on the same principle. Another type of device, a capacitance based sensor, works in a similar way, but instead of a changing resistance, it measures a changing capacitance that can be correlated to stretch and strain.

We have identified commercially available "stretch" gages and a number of available conductive materials that can be used as strain sensors. A list of the devices and materials under review is shown in Table 1 below and described as:

1) The High Elongation Foil Strain Gage is a typical metallic gage, but uses a substrate that allows for greater elongations up to $10 \%$. We will adhere the gages directly to a broadcloth and strap to get strain measurements.

2) A Conductive Paint or RTV changes resistance based on surface area and volume. We can paint the conductive material directly onto the surface of the strap and measure the change in resistance as it is pulled in tension.

3) A Conductive Thread Coverstitch is a new device developed with a collaboration at the University of Minnesota as a stretch sensor for smart clothing. The conductive thread is stitched in a way that changes the resistance as it is stretched. The device can be sewn into the broadcloth material directly.

4) The Conductive Polymer Cord is used in robotics as a stretch sensor and acts like a rubber band that changes resistance as it is stretched and released. It can be adhered or sewn at its ends directly into the material.

5) NanoSonic Metal Rubber is made by NanoSonic Inc. from Virginia. It is a highly elastic conductive material that can be adhered or sewn into a substrate and changes resistance as it is stretched. 
6) The StretchSense Fabric Sensor is a capacitive based stretch sensor made by StretchSense Ltd. from New Zealand. The sensor is commercially available and has an integrated battery, circuit board and Bluetooth module for data logging on a Bluetooth-enabled device. It is made of fabric and can be directly stitched into the broadcloth.

Table 1. List of devices being evaluated.

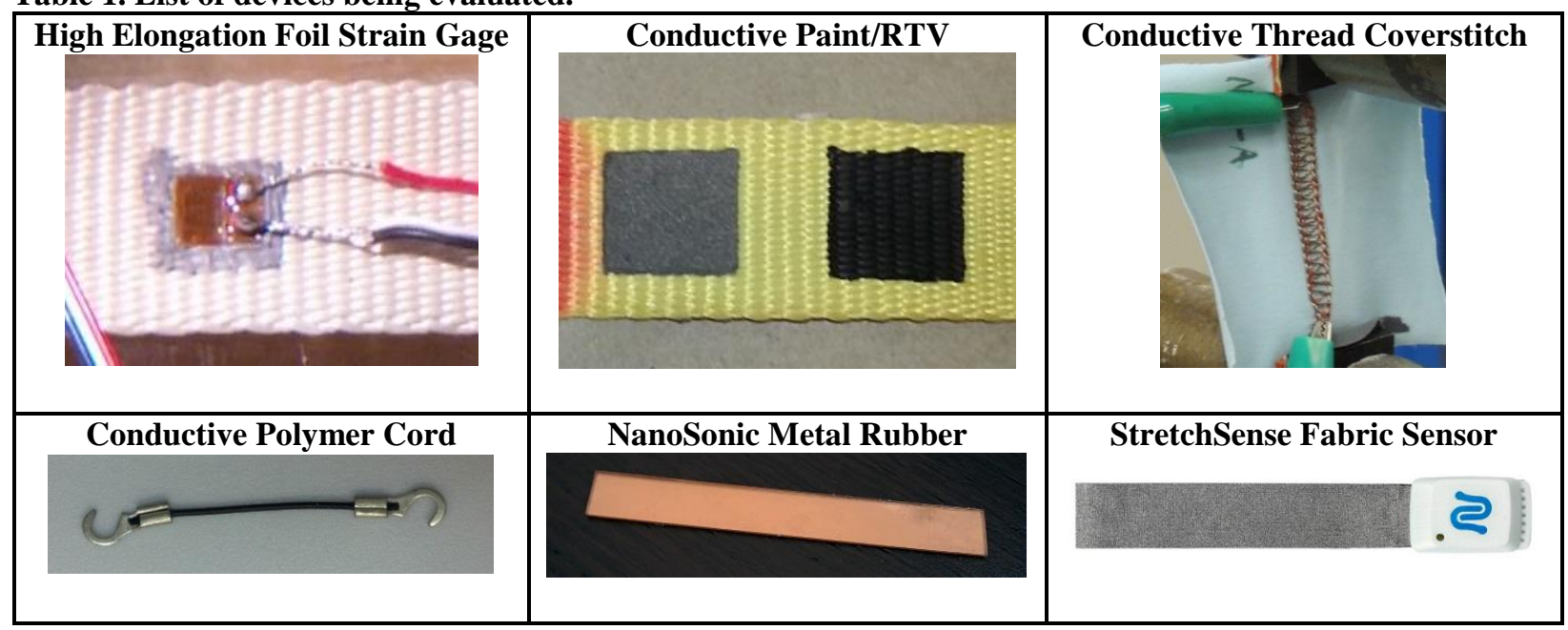

\section{Test Program}

The candidate gage devices will be evaluated in a series of mechanical tests to compare their performance. The tests include:

a) Low-rate tensile tests to evaluate their sensitivity to small changes in length.

b) Long-term creep tests to record any loss of signal under a sustained load.

c) Cyclic tests to identify any hysteresis or timing issues of the resistivity changes over cyclic loading.

Beside these three main tests, additional testing will be completed to evaluate the device's adhesion with the substrate material. Additional considerations such as packaging, electrical resources, electro-magnetic interference (EMI), and thermal effects, will be evaluated in future phases of this investigation.

\section{Test Results}

Each gage device was tested using an electro-mechanical load frame under displacement control with a constant displacement. The devices themselves were stretched and evaluated according to the tests outlined in Section V above. While the initial phase of testing evaluated the device only, a scond phase of testing was completed on some of the candidate devices that integrated the device onto a fabric substrate to test the integrated performance. 


\section{A. High Elongation Foil Strain Gage}

As a widely used device for strain measurement of metallic structures, a foil strain gage was considered for strain measurement on a fabric substrate. A foil gage provides reliability, accuracy and a well established line of hardware and procedures for test data. These gages, however, are designed for metallic and some for composties, but never for fabrics. The biggest issue is that typical foil gages have a max elongation that is much smaller than the elongation seen in a fabric structure. Therefore, we need high-elongation foil gages and new adhesive methods to ensure that strain is properly transferred from the fabric to the gage.

Linear pattern foil strain gages were adhered to a Kevlar strap to evaluate the performance of a foil gage on a material substrate that exibits high strain. The gages were adhered using two different adhesive materials: Silicone RTV142 and EA3934 Structural Epoxy as shown in Figure 5. These materials are common in the aerospace industry but offer very differnet properties. The RTV is a one-part paste material with $400 \%$ elongation, while the epoxy is a two-part material intended for high strength structural capability and offers only $2 \%$ elongation.

The adhesive materials were first applied to the surface of the strap, then the gages were installed over the uncured adhesive and allowed to fully cure with applied pressure in a co-curing process. Once cured, the gages were wired and soldered.

Tensile testing was completed on the strap with the gages installed. The strap is rated to 6,000 lbf and was loaded to 4,200 lbf at a constant displacement rate.

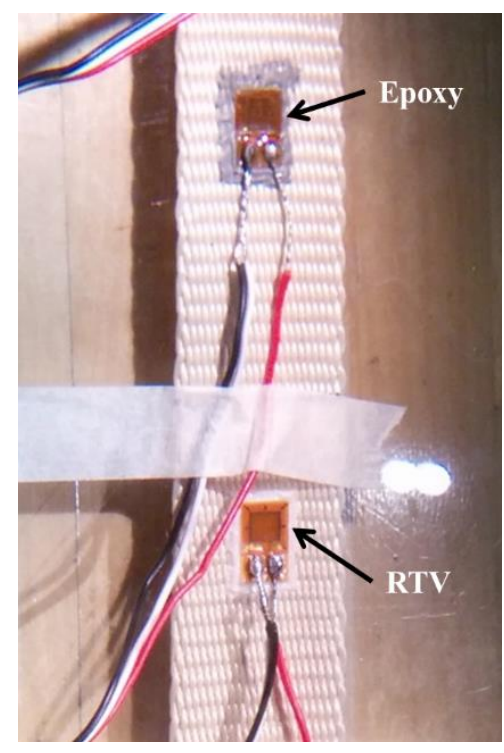

Figure 5. Test strap with foil strain gages installed using epoxy and RTV.

The strain gages were each connected to a quarter Wheatstone bridge circuit and data acquisition system. Test results are shown in Figure 5 that reveal obvious differences between each adhesive material. The first thing to note is that the strap experienced slippage during the test, which was captured by the strain gages and are represented by small spikes in the strain data. The second note is that both strain gages experienced a plateu of strain measurement as shown in the figure. This plateu is likely due to the strain gages peeling from the adhesive materials. With extended loading to higher strains, we experienced failure of the gages by disbonding from the adhesive. The third observation is that the epoxy adhesive is much stiffer than the strap and its associated gage sees a lower strain at the stiffened region than the rest of the strap. The RTV material, however, is not as stiff as the strap and actually provides a substrate for the gage that shows a higher strain than the rest of the strap. Because of these differences, neither of these materials is ideal for use as a strain gage adhesive.

The HIAD project mentioned above, used high elongation strain gages and an epoxy resin that is typically used on a composite material as the adhesive for the strain gage ${ }^{4}$. The HIAD procedure involved applying the epoxy resin to the substrate, curing the resin, then adhering the strain gage to the cured resin (instead of co-bonding the strain gage to the resin itself). This procedure produced good adhesion and good results on a Kevlar substrate through ground and flight tests of HIAD and shows promise for use on inflatable structures. 


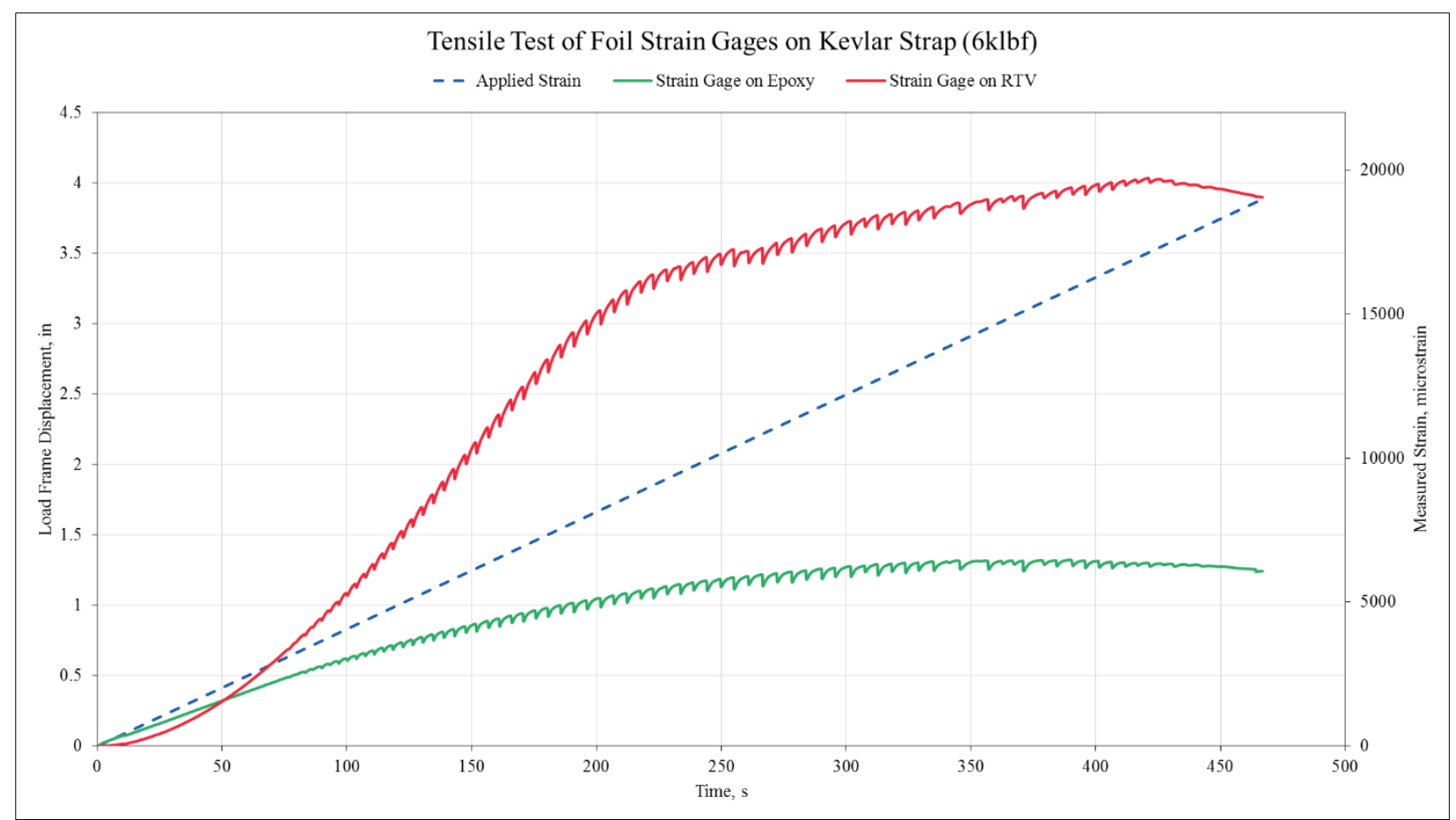

Figure 6. Tensile test results of foil strain gages on a Kevlar strap using epoxy and RTV adhesive methods.

\section{B. Conductive Paint/RTV}

Conductive polymer materials were considered for strain measurement devices because they can be applied directly to the surface of a fabric and still provide flexibility. The materials are conductive and provide an internal resistance than changes when the material or fabric is stretched. Two materials were evaluated in this program, a conductive paint and a conductive RTV. The paint is Bare Conductive Paint and the RTV is a Nickel Graphite infused silicon, and both products are commercially available.

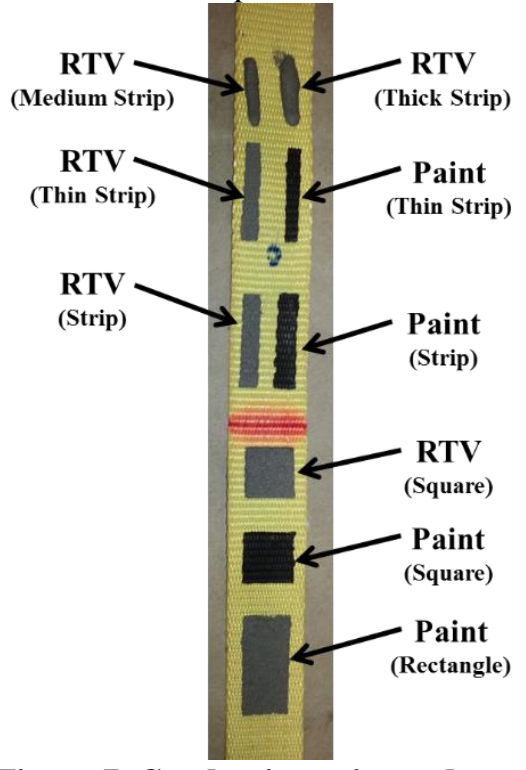

Figure 7. Conductive paint and RTV on a Kevlar strap for evaluation of different patch sizes.
To evaluate the materials, both products were applied directly to the surface of a Kevlar strap. The Bare paint is a water-based paint that is applied smoothly to the strap, while the RTV is thick, full of conductive particles, and difficult to apply to a strap. The first test on a strap evaluated differnet sized and shaped patches as shown in Figure 7. It was found that a square patch of material produced the best result. The next iteration painted square patches of paint and RTV onto a strap as shown in Figure 8. A full Wheatstone bridge circuit was used on each patch to measure an output voltage against and applied input voltage.

The strap was tested in tensile, creep and cyclic evaluations. Six patches were compared, as shown in Figure 8 , during the tests. The best results for each patch are shown in

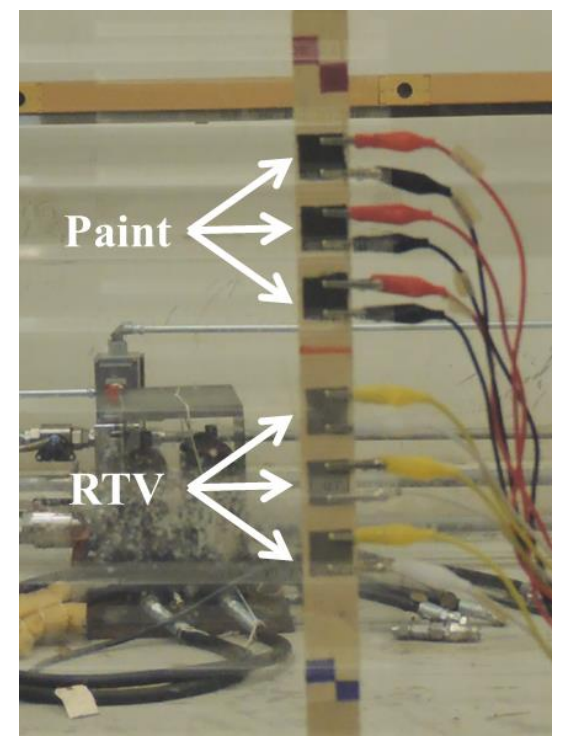

Figure 8. Conductive paint and RTV patches on a Kevlar strap during a structural test. 
Figures Figure 9 - Figure 11. The tensile test with the best results was the conductive paint with three layers, shown in Figure 9. The paint produced a linear trend with some noise, that followed the expected results. It was also found that over high strains (> 150\% initial length), the conductive RTV material exhibited cracking and the voltage dropped. Cracking was not found in the paint material. The creep test on the conductive paint, shown in Figure 10, shows a significant drop in voltage during the hold region. It is speculated that the polymer nature of the material is causing this drop in voltage. When polymers are stretched, the polymer chains begin to relax and stretch out to relieve the strain in the material. The cyclic test, Figure 11, shows a similar hysteresis result with a drop in voltage over six cycles. These voltage drops would cause significant issues when trying to use these materials for long term SHM.

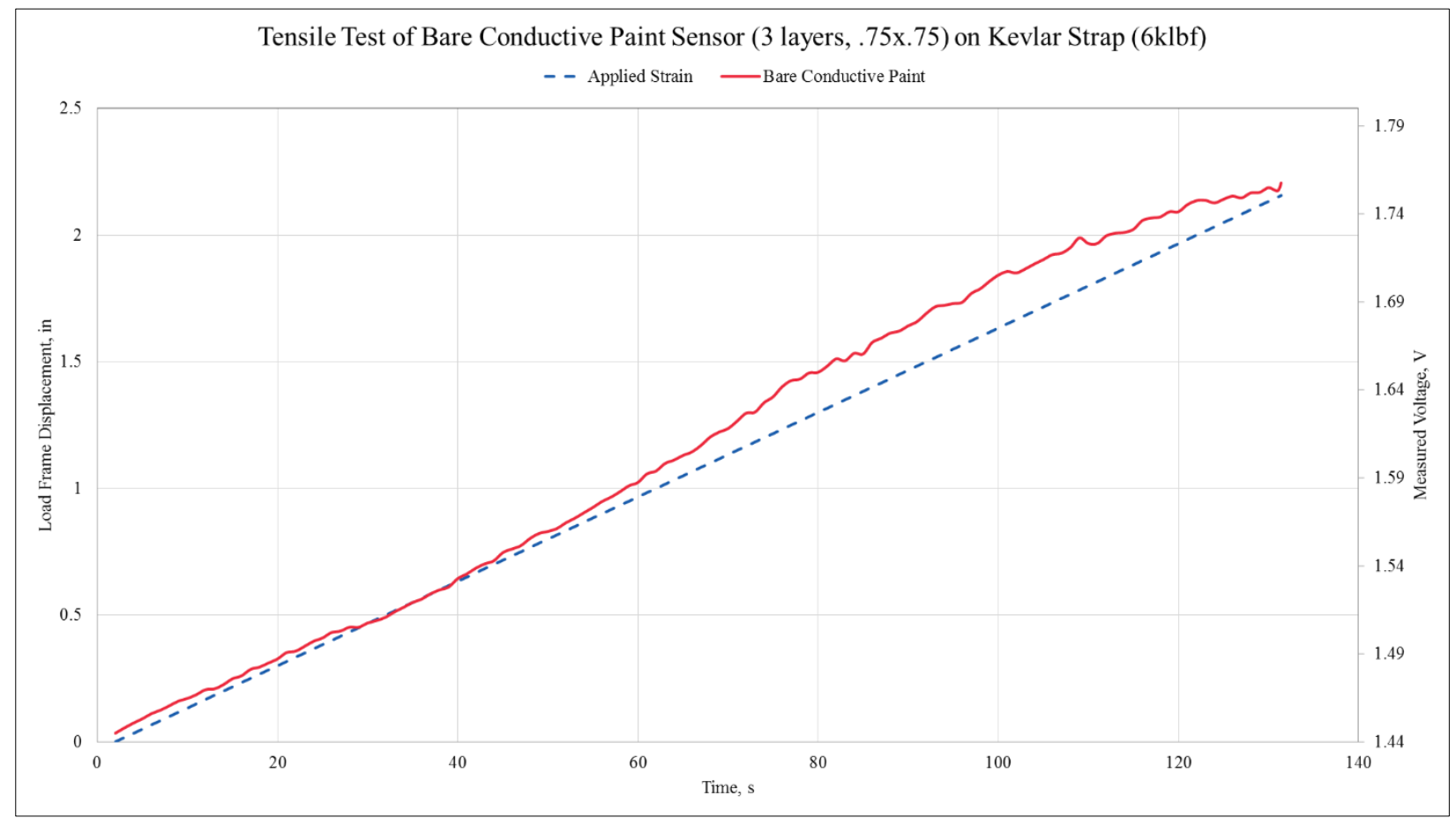

Figure 9. Tensile test result of Bare Conductive paint sensor on a Kevlar strap. 


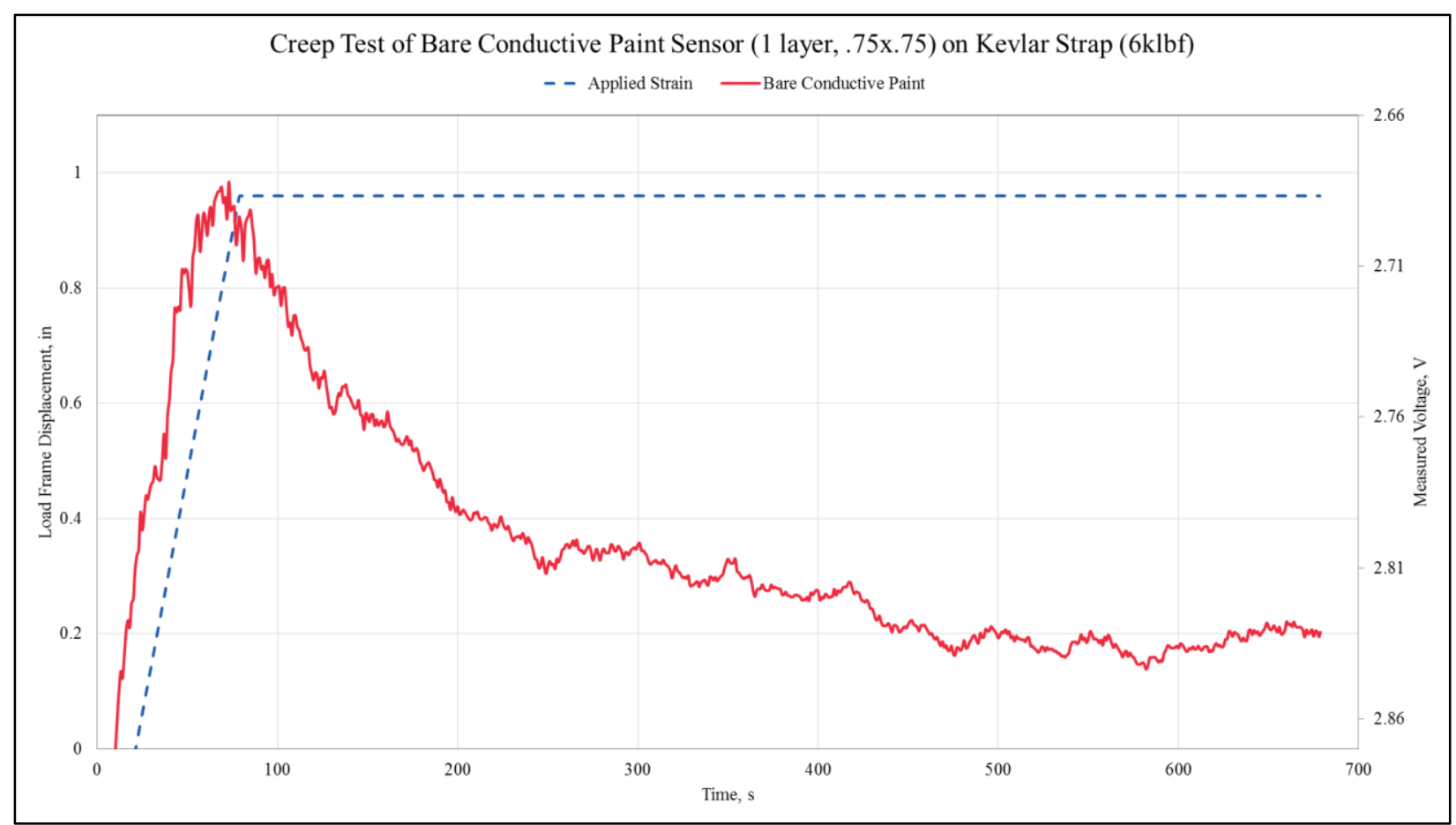

Figure 10. Creep test result of Bare Conductive Paint Sensor on a Kevlar strap.

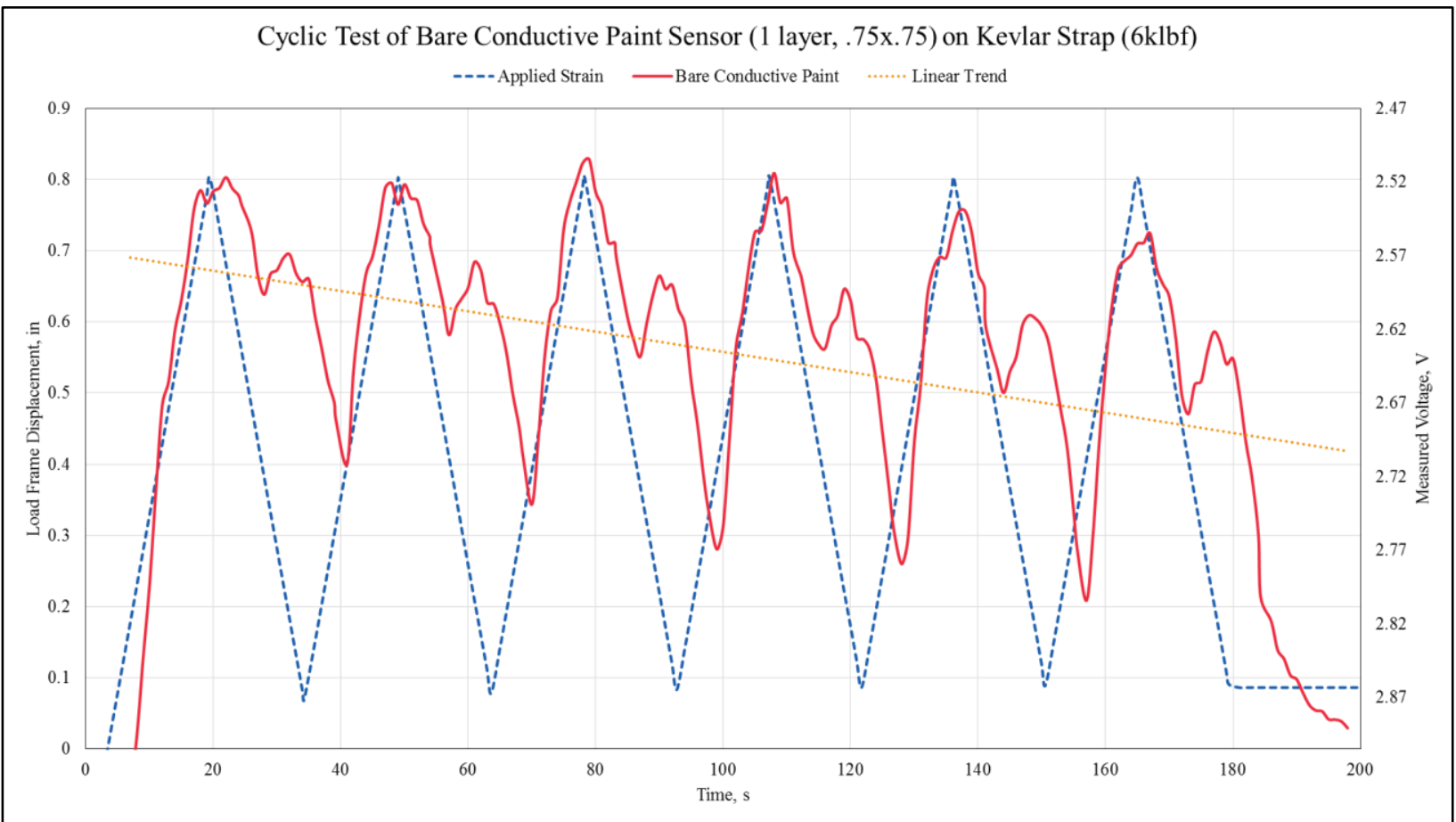

Figure 11. Cyclic test result of Bare Conductive Paint Sensor on a Kevlar strap. 


\section{Conductive Thread Coverstitch}

The conductive coverstitch sensor uses conductive threads that are sewn in a coverstitch pattern. This pattern allows the threads to contact one another and move relative to each other as the stitch is stretched ${ }^{5}$. The sensor has an internal resistance that changes as the stitch is stretched. The stitch can be created using a sewing machine at a low cost and in a very short amount of time.

The conductive coverstitch sensor was stitched into small samples of neoprene fabric to test the performance on a substrate with high elongation as shown in Figure 12. The samples were installed in a load frame and tested for tensile, creep, and cyclic performance. An input voltage was applied to the sensor and the output voltage was measured using a full Wheatstone bridge circuit.

Figure 13 shows the result of the tensile test where the sensor was stretched to $150 \%$ of its initial length at a constant displacement rate. The sensor produced excellent results that followed a linear trend, matching the expected result, but with some noise in the data. The noise was seen in all tests of this sensor due to the exposed nature of the coare threads

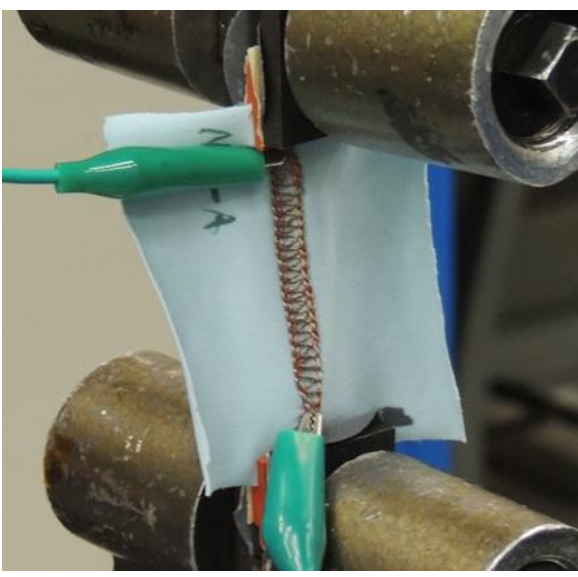

Figure 12. Conductive coverstitch on a neoprene sample in a load frame. contacting each other. The creep test result is shown in Figure 14 that shows a similar linear increase up to 150\% and then held for a few seconds. The coverstitch sensor shows increasing voltage during the initial increase and additional increase during the hold region. The cyclic test, shown in Figure 15 shows similar results with a decreasing trend in voltage after 20 cycles.

The advantage with the coverstitch design is that is can be installed directly onto a substrate. To demonstrate this capability, we installed a coversttich onto a Kevlar strap, as shown in Figure 16. The results matched that seen with the stitch on a neoprene substrate. These results follow the observed behavior of resistive type sensors with the tendancy for hysteresis in the voltage during cyclic and hold tests. This type of sensor does produce good results for a short period of time and for large voltage changes, but cannot be used accurately for SHM over extended period of time and for very small changes in voltage.

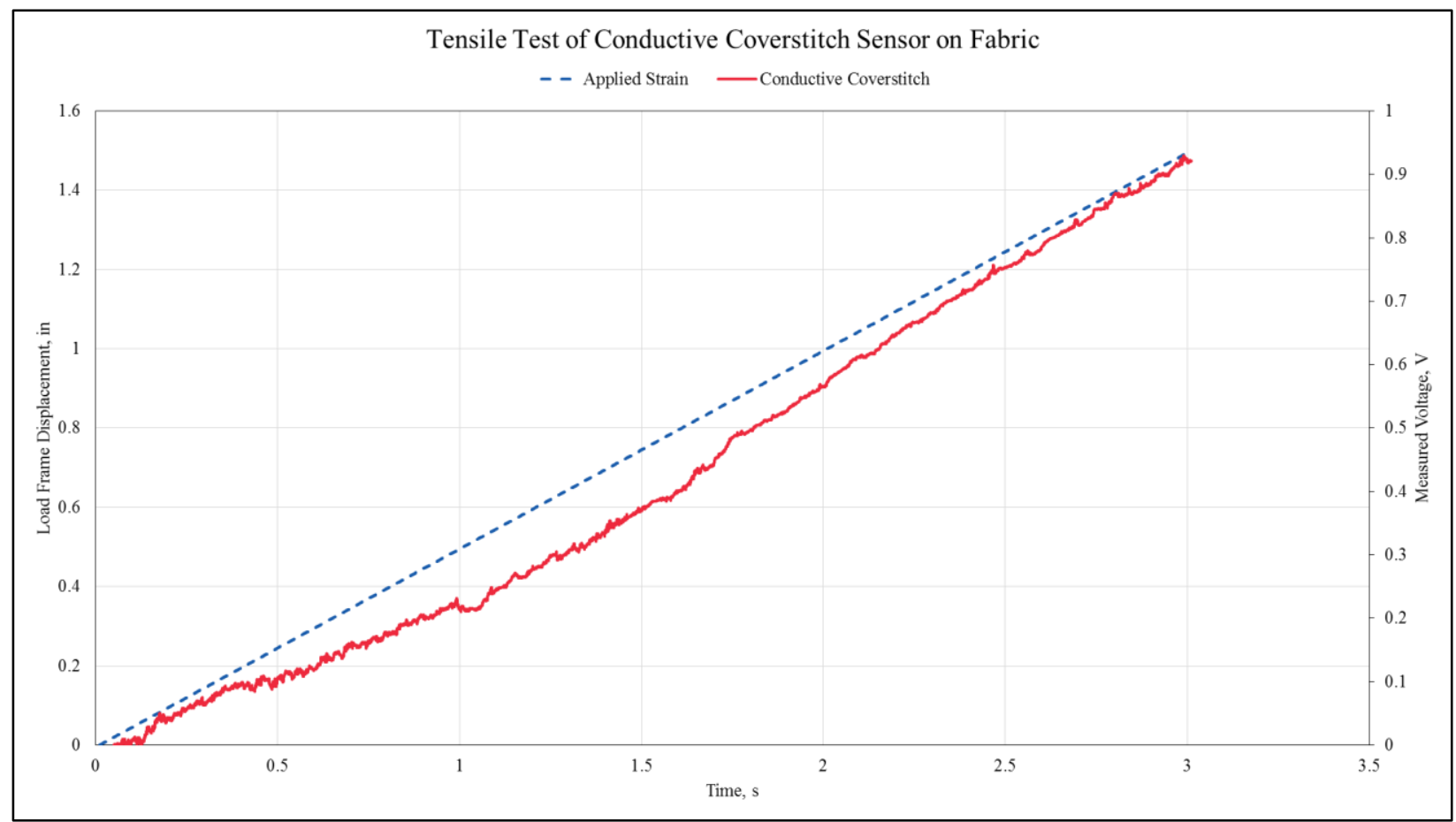

Figure 13. Tensile test result of Conductive Coverstitch sensor on fabric. 


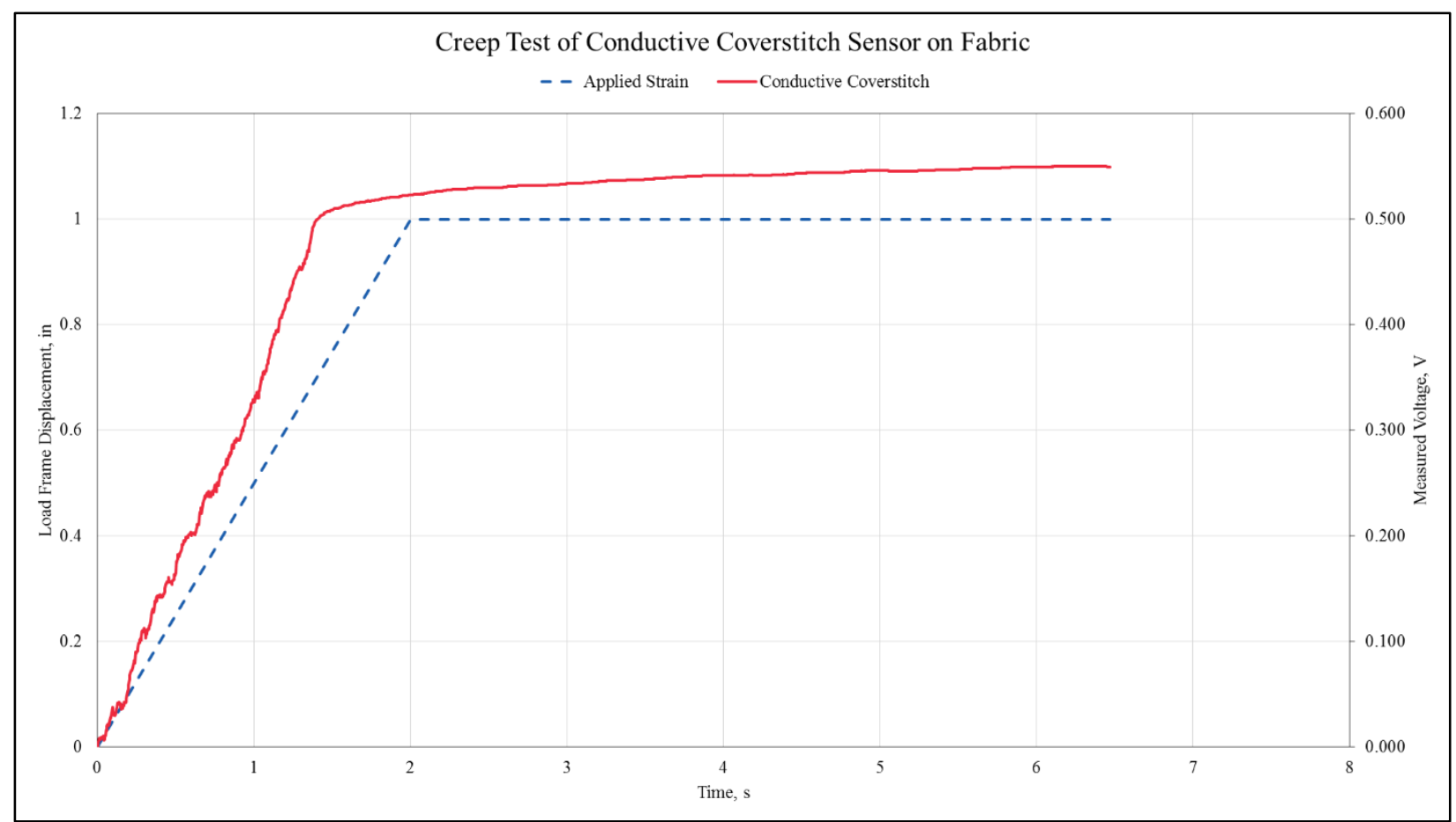

Figure 14. Creep test result of Conductive Coverstitch sensor on fabric.

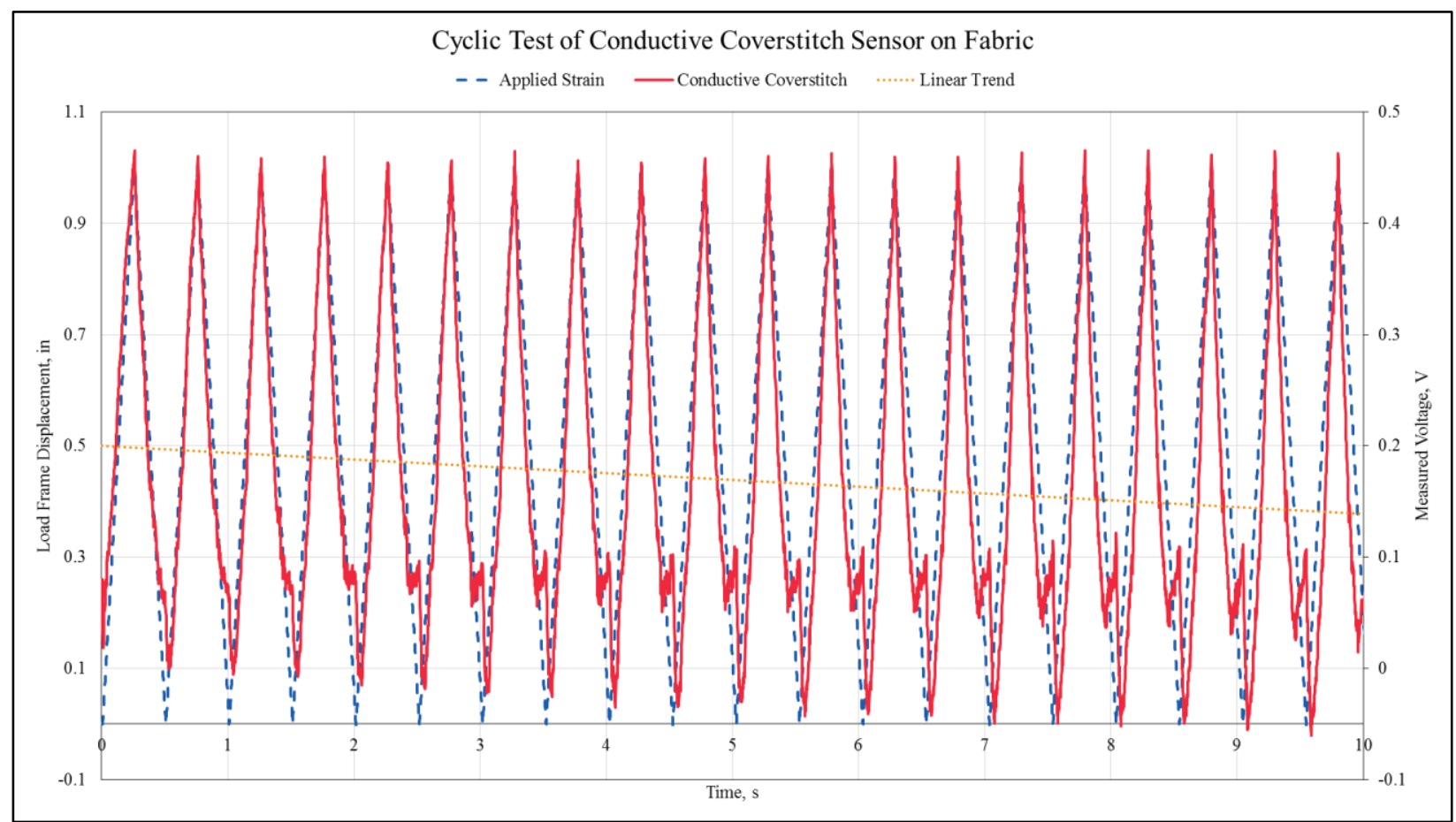

Figure 15. Cyclic test result of Conductive Coverstitch sensor on fabric.

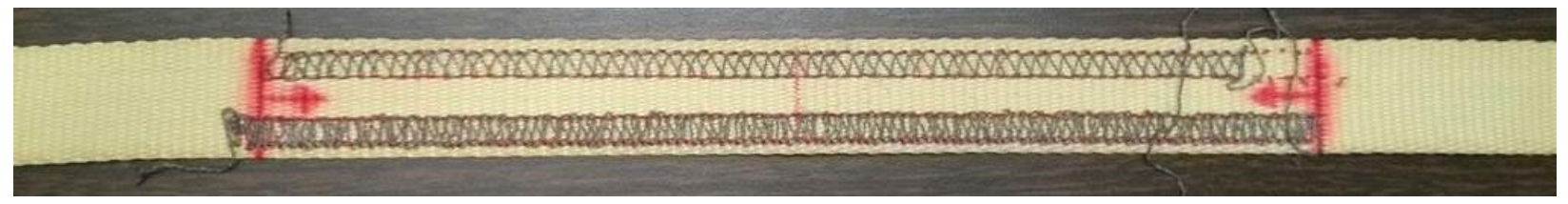

Figure 16. Conductive Thread Coverstitch sensor sewn into a Kevlar strap.

American Institute of Aeronautics and Astronautics 


\section{Conductive Polymer Cord}

A conductive cord material was found commercially that looks and behaves similar to a rubber band that is conductive, as shown in Figure 17. The internal resitance of the cord changed as the length of the cord changes and can thus be used as a stretch sensor. The conductive cord sensor was tested in the same manner as the conductive coverstitch. It was installed without a substrate, directly into a load frame and tested for tensile, creep, and cyclic performance up to $150 \%$ of the initial

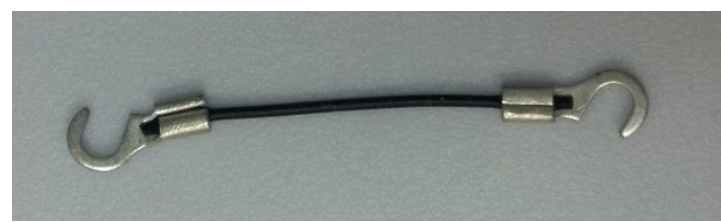

Figure 17. Conductive polymer cord sensor. length. An input voltage was applied and the output voltage was measured directly.

The tensile test result, shown in Figure 18, shows an excellent linear trend with little to no noise in the signal. The creep test result, in Figure 19, shows a similar linear trend region and then a relaxing voltage during the hold region. During long term creep tests, it was shown that the voltage drops almost completely back to the initial voltage while being held at a constant load. This drop in voltage is speculated to be a property of the polymer material that makes up the cord, similar to the result seen in the conductive paint. The cyclic performance, shown in Figure 20, was similar to the conductive coverstitch with hysteresis and decreasing voltage over 20 cycles.

To test the integration with a strap, the polymer cord was installed on a Kevlar strap substrate as shown in Figure 21. It was simply stitched at either end to rigidly attach it to the strap. The combined system perfomed well for a simple tensile test, but produced the same voltage hysteresis for creep and cyclic tests. Because of these results, this sensor is not a good candidate for lifetime SHM of an inflatable.

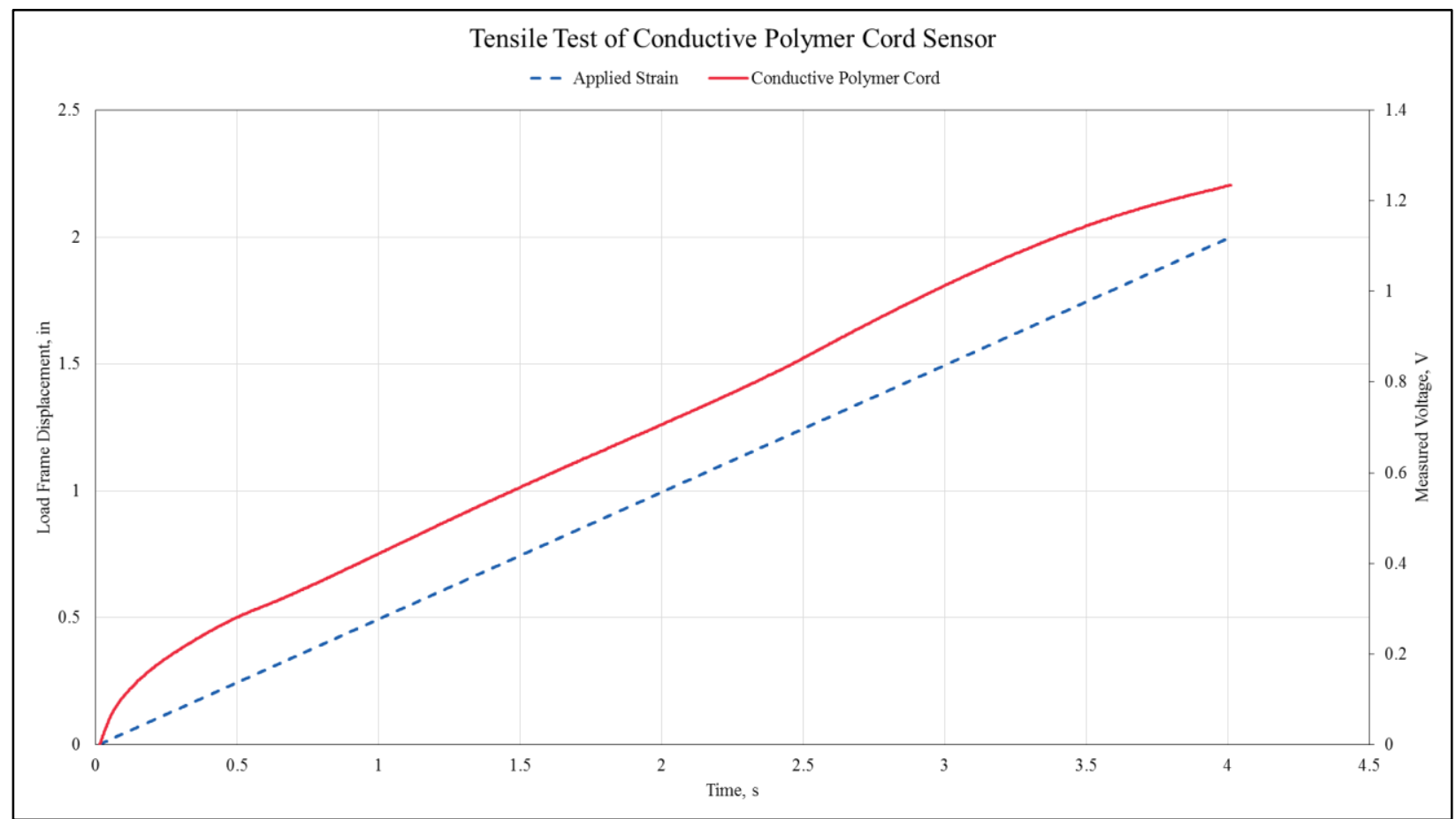

Figure 18. Tensile test result of conductive polymer cord sensor. 


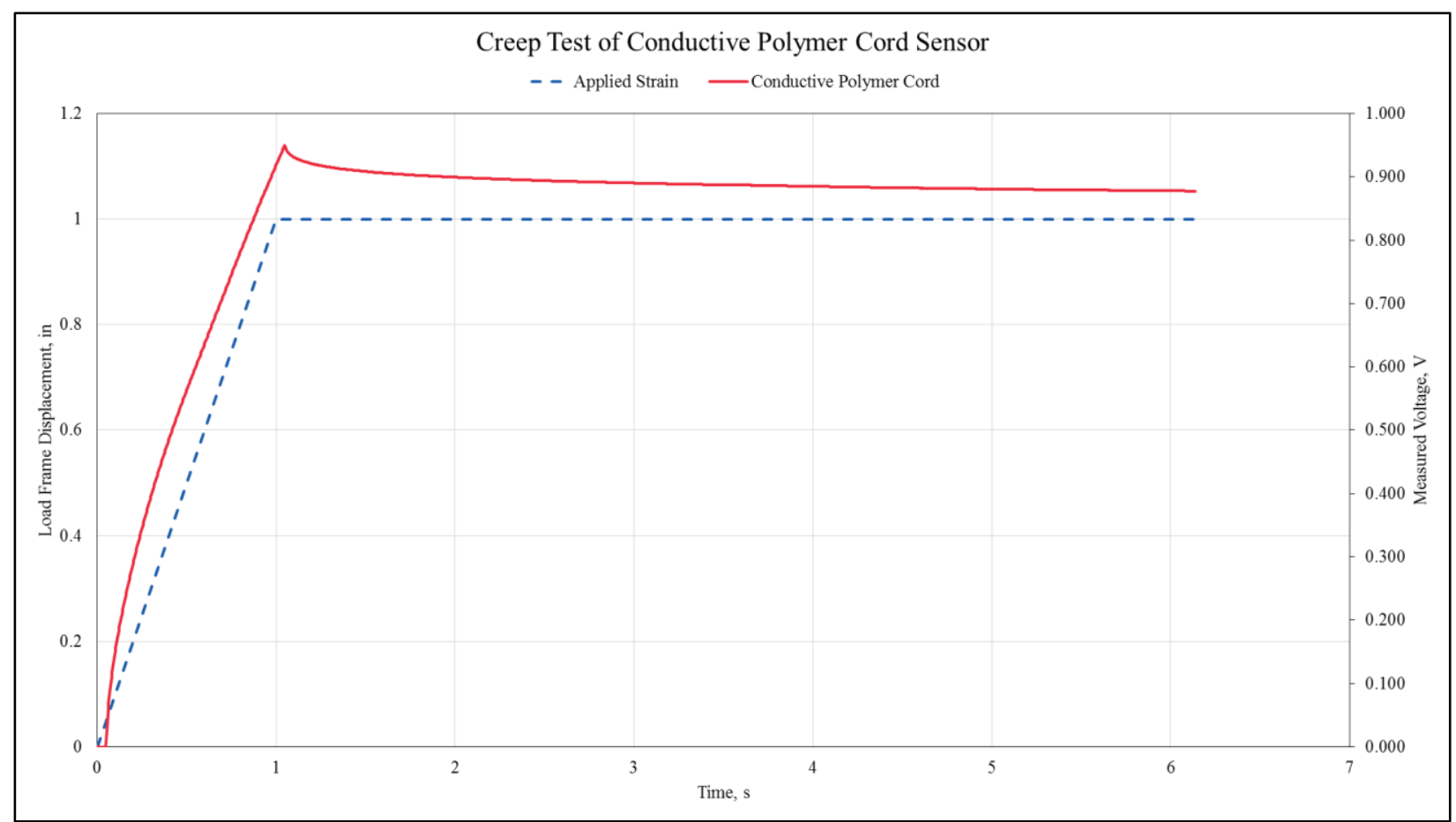

Figure 19. Creep test result of a conductive polymer cord sensor.

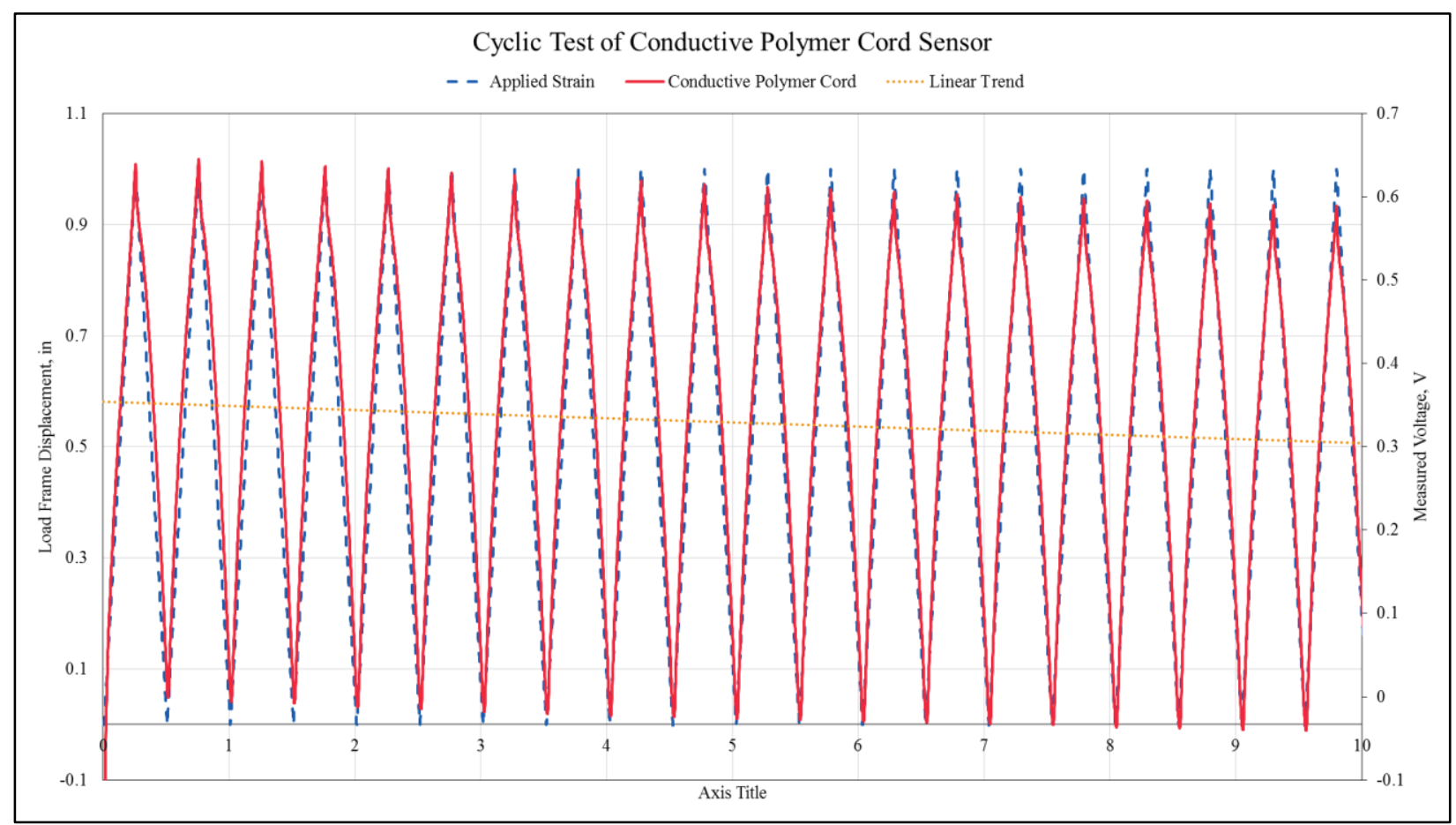

Figure 20. Cyclic test result of a conductive polymer cord sensor.

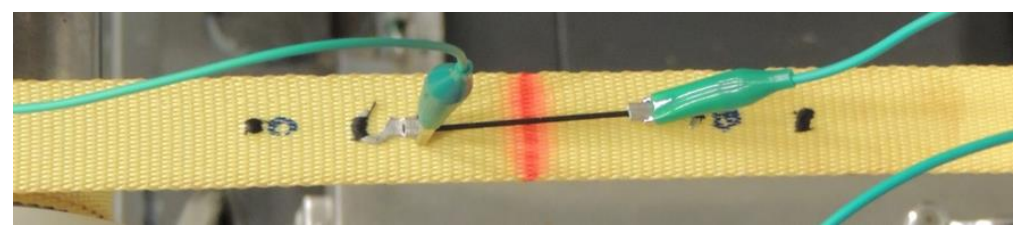

Figure 21. Conductive polymer cord integrated with Kevlar strap.

American Institute of Aeronautics and Astronautics 


\section{E. NanoSonic Metal Rubber}

Metal Rubber material is a highly elastic thin polymer with a conductive layer that can be stretched to $200 \%$ of its initial length. When cut in a rectangular shape, the material can be used as a stretch sensor by measuring the change in resistance as the material is stretched. This technique was evaluated by the NASA High Altitude Science Balloon program with promising results ${ }^{6}$. In that case, the sensors were used to measure the tension in cylindrical cordage, but for inflatable habitats, the sensors would be adhered directly to the surface of the strap.

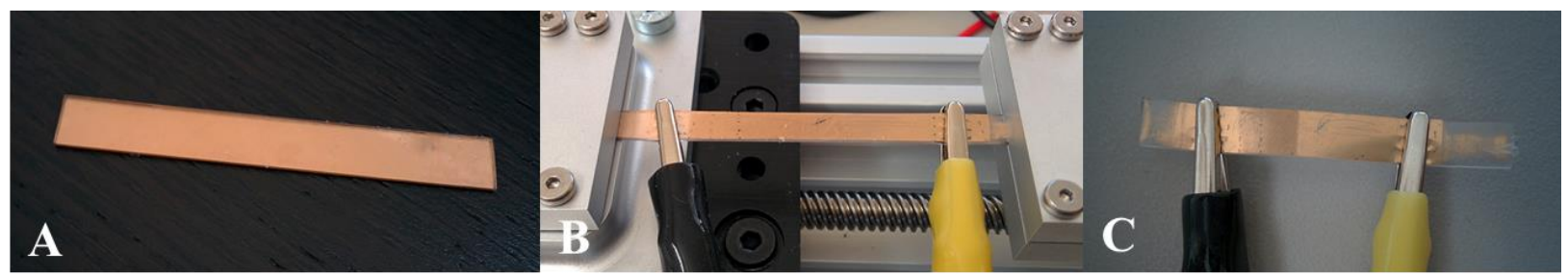

Figure 22. NanoSonic Metal Rubber sensors before, during, and after tensile testing. A) Pristine sensor prior to testing. B) Sample during tensile testing. C) Sample after testing was completed.

For our testing, we completed tensile and creep testing of the rubber material without a substrate, as shown in Figure 22. A full Wheatsone bridge was used to apply a voltage to the device and the output voltage was measured. The test results are shown in Figure 23. As the sample was tensioned, we noticed that the conductive layer was showly degrading as it was being stretched. The figure shows that there is a peak resistance in the material and once it was stretched over that peak, the signal was lost. When the load was lowered, the signal returned, although it showed a degrading voltage over an extended period of time. As see in Figure 22, the strength of the conductive layer was weak and simply using alligator clips on the sensor was causing degredation. Stretching of the sensor also caused damage to the conductive layer. The material was identified as too fragile and sensitive for health monitoring applications on inflatables.

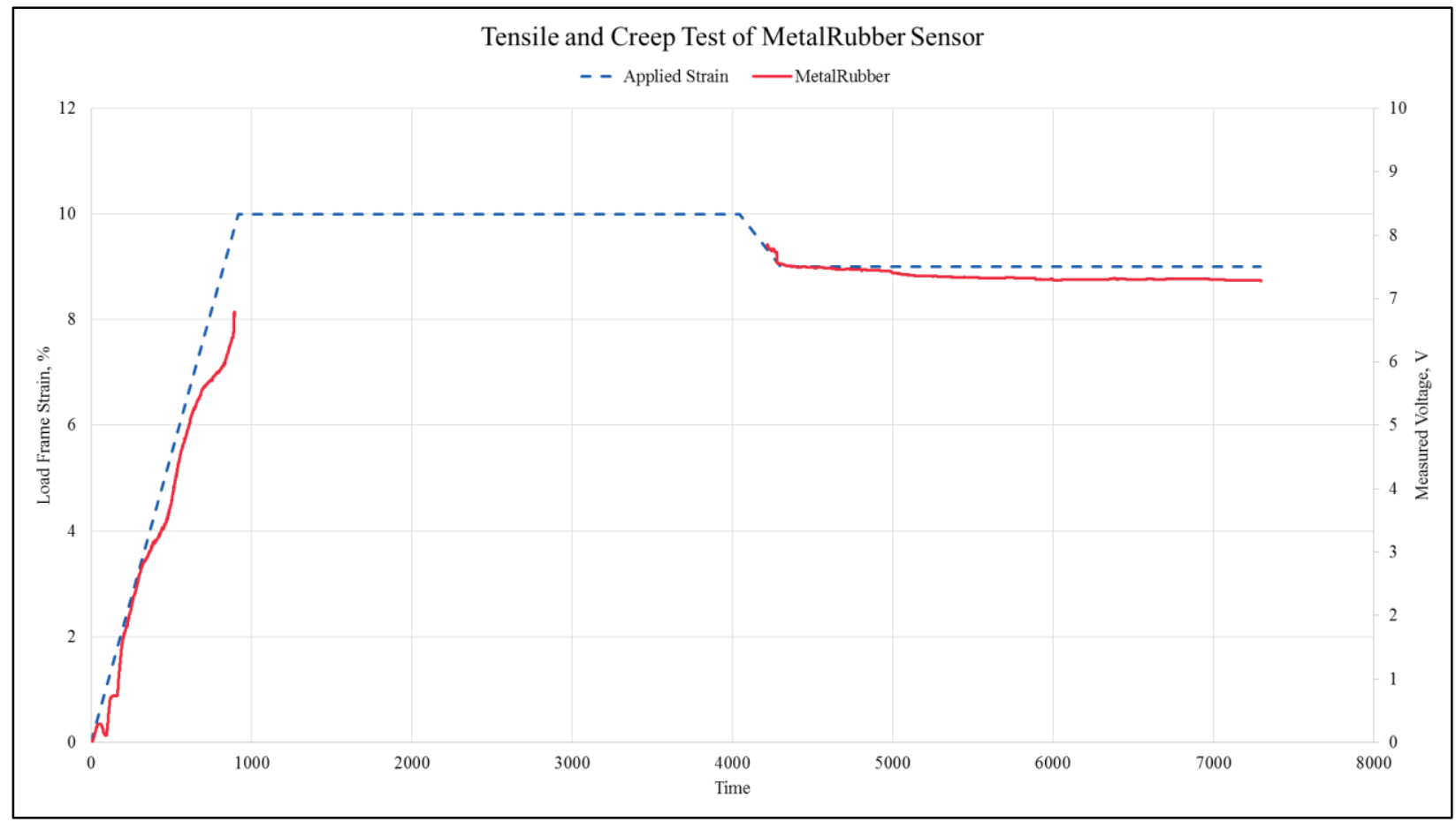

Figure 23. Tensile test result of NanoSonic Metal Rubber sensor. 


\section{F. StretchSense Fabric Sensor}

The StretchSense Fabric sensor is a capacitance based stretch sensor that is commericaly available and comes with a Bluetooth data acquisision application for mobile devices, as shown in Figure 24. The sensor is made of layers of flexible fabrics that are combined to form a capacitor. The capacitance in the device changes as the sensor is stretched. Because the sensor is made of fabric, it is extremely flexible and can be directly adhered or stitched into a substrate.

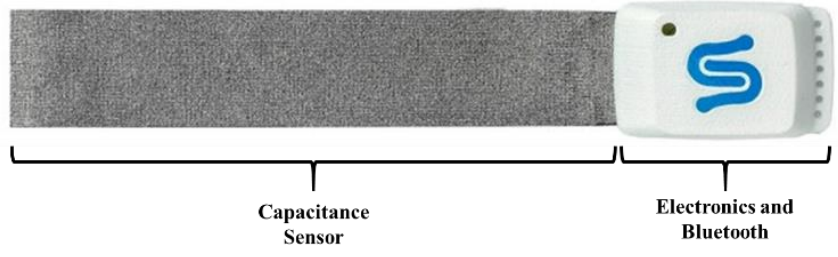

Figure 24. StretchSense Fabric sensor layout.

Testing of the sensor was completed by installing the device into a load frame without a substrate. The tensile test result is shown in Figure 25. The sensor produced excellent response compared to the applied strain, with minimal noise in the data. The creep test, shown in Figure 26, shows the best creep performance out of any of the sensors. There is little to no voltage drop or hysteresis in the signal over time. Additional long term creep testing was also completed and is shown in Figure 27. This shows that the sensor can produce very consistant readings over an extended period of time. The cyclic performance of the gage was not yet evaluated, due to the lack of a controlled load frame at the time of testing. Uncontrolled testing of cyclic performance produced excellent results and showed that the sensor is extremely sensitive, even at very low strains.

The capacitice-based device, compared to the resistance-based devices, offers little to no hyterisis in the signal for creep and cyclic testing. This measure, along with its sensitivity and accuracy, make the StretchSense device the best choice, out of those evaluated here, for SHM for inflatable structures.

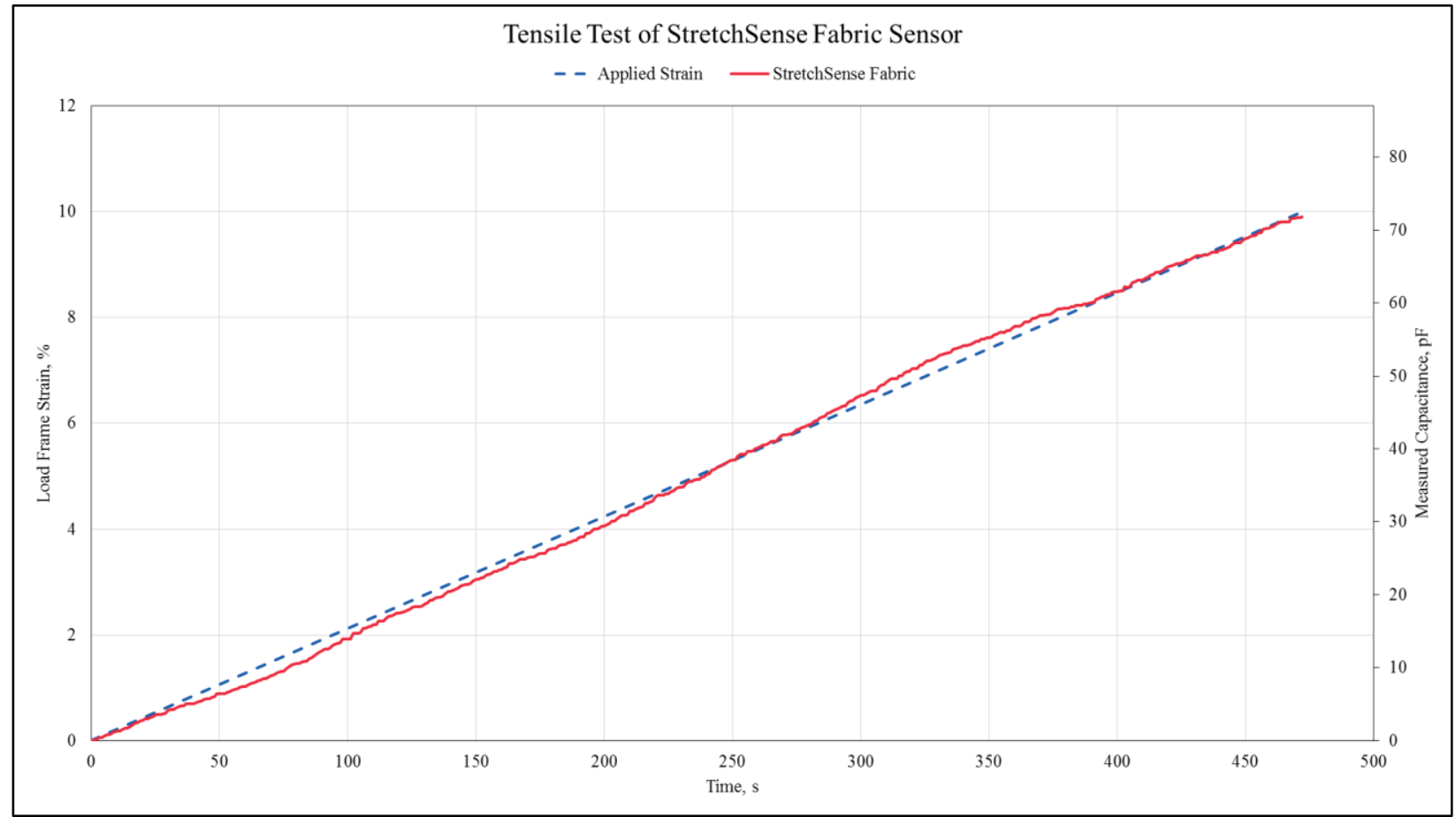

Figure 25. Tensile testing result of StretchSense Fabric sensor. 


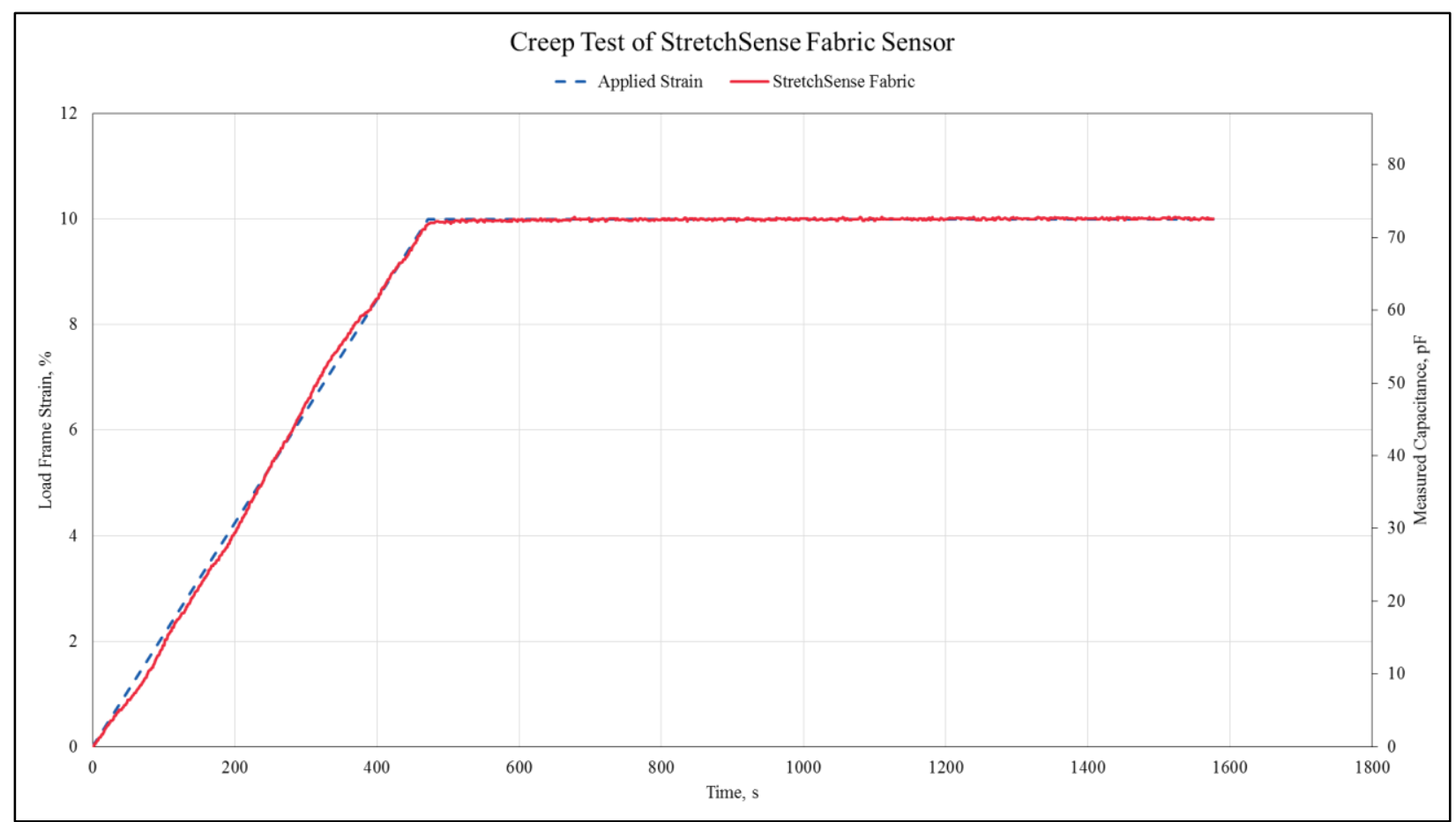

Figure 26. Creep testing result of StretchSense Fabric sensor.

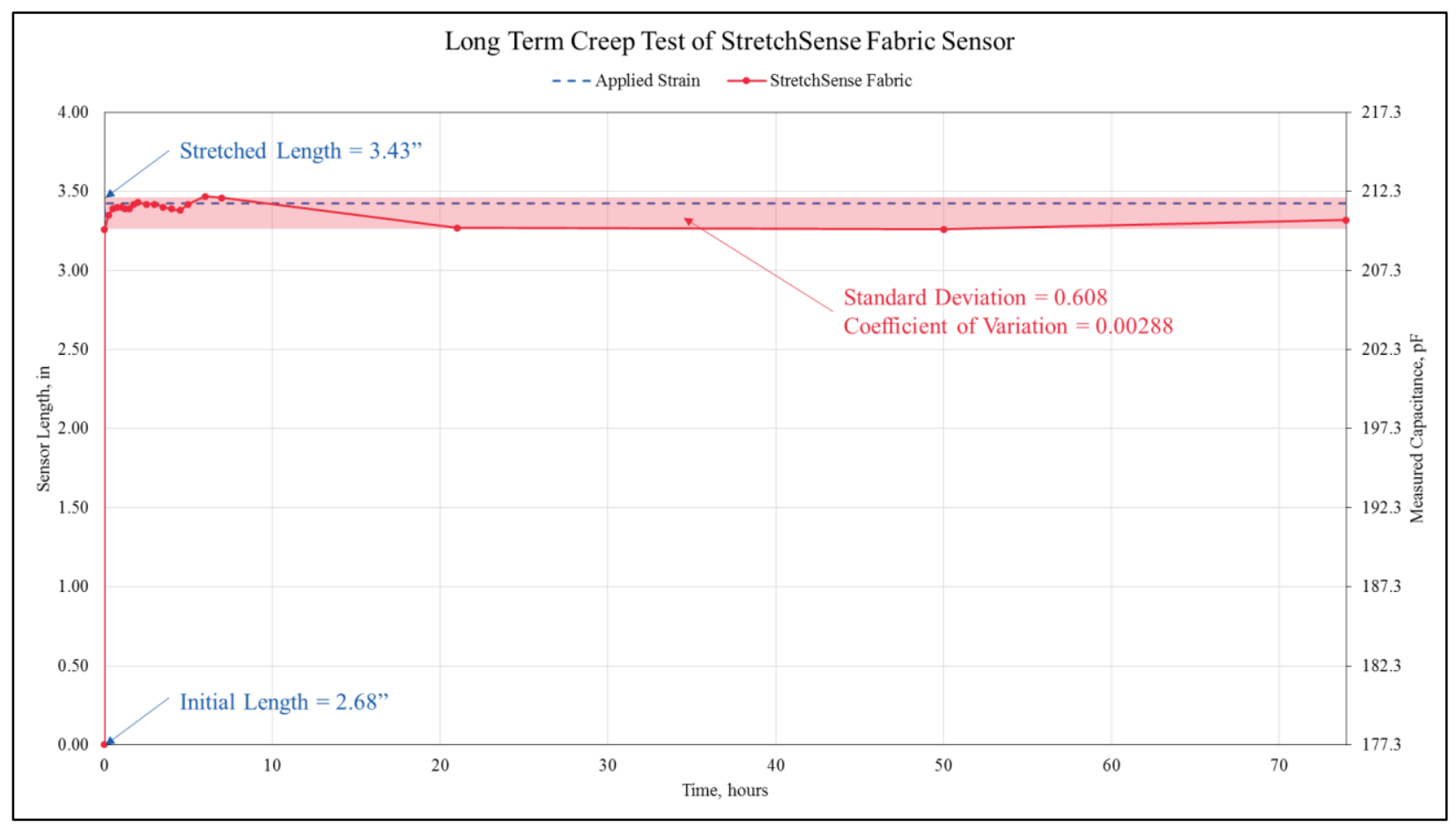

Figure 27. Long term creep test result of StretchSense Fabric sensor. 


\section{Conclusions}

The strain gage devices evaluated in this program provide insight into the performance characteristics of potential structural health monitoring systems for inflatable structures. Six potential devices were evaluated using structural considerations. A comparison summary of all devices is shown in Table 2 below. The foil strain guage and the StretchSense sensor are the only two devices that will continue development. Although the foil gage showed poor performance in this test, it has proven to be successful in the NASA HIAD project and could be successful for inflatable habitats with the optimal installation procedure. The StretchSense device proved to be the prime sensor with excellent results in all the tests. This device will be tested further and evaluated as a SHM solution. The other devices that were tested proved to have weaknesses and general hysteresis in the signal for creep and cyclic testing, which is insufficient for long term health monitoring.

Table 2. Strain gage device summary of results.

\begin{tabular}{|c|c|c|c|c|c|c|}
\hline & $\begin{array}{c}\text { High } \\
\text { Elongation } \\
\text { Foil Strain } \\
\text { Gage }\end{array}$ & $\begin{array}{l}\text { Conductive } \\
\text { Paint/RTV }\end{array}$ & $\begin{array}{l}\text { Conductive } \\
\text { Thread } \\
\text { Coverstitch }\end{array}$ & $\begin{array}{l}\text { Conductive } \\
\text { Polymer } \\
\text { Cord }\end{array}$ & $\begin{array}{c}\text { NanoSonic } \\
\text { Metal } \\
\text { Rubber }\end{array}$ & $\begin{array}{c}\text { StretchSense } \\
\text { Fabric } \\
\text { Sensor }\end{array}$ \\
\hline Electronics & Resistive & Resistive & Resistive & Resistive & Resistive & Capacitive \\
\hline $\begin{array}{l}\text { Installation } \\
\text { Method }\end{array}$ & $\begin{array}{l}\text { Adhere to } \\
\text { surface using } \\
\text { resin/adhesive }\end{array}$ & $\begin{array}{l}\text { Paint directly } \\
\text { onto surface }\end{array}$ & $\begin{array}{l}\text { Stitch } \\
\text { directly into } \\
\text { substrate }\end{array}$ & $\begin{array}{l}\text { Adhere to } \\
\text { surface }\end{array}$ & $\begin{array}{l}\text { Adhere to } \\
\text { surface }\end{array}$ & $\begin{array}{l}\text { Adhere to } \\
\text { surface }\end{array}$ \\
\hline $\begin{array}{l}\text { Tensile } \\
\text { Performance }\end{array}$ & $\begin{array}{l}\text { Poor linear } \\
\text { trend due to } \\
\text { adhesive } \\
\text { methods used }\end{array}$ & $\begin{array}{l}\text { Good linear } \\
\text { trend with } \\
\text { some noise }\end{array}$ & $\begin{array}{l}\text { Good linear } \\
\text { trend with a } \\
\text { lot of noise }\end{array}$ & $\begin{array}{l}\text { Great linear } \\
\text { trend with } \\
\text { very little } \\
\text { noise }\end{array}$ & $\begin{array}{l}\text { Good linear } \\
\text { trend up to } \\
\text { material } \\
\text { limit }\end{array}$ & $\begin{array}{l}\text { Excellent } \\
\text { linear trend } \\
\text { with little } \\
\text { noise }\end{array}$ \\
\hline $\begin{array}{l}\text { Creep } \\
\text { Performance }\end{array}$ & N/A & $\begin{array}{l}\text { Severe } \\
\text { hysterisis }\end{array}$ & $\begin{array}{l}\text { Slight } \\
\text { hysteresis }\end{array}$ & $\begin{array}{l}\text { Slight } \\
\text { hysteresis }\end{array}$ & $\begin{array}{l}\text { Slight } \\
\text { hysteresis }\end{array}$ & No hysterisis \\
\hline $\begin{array}{l}\text { Cyclic } \\
\text { Performance }\end{array}$ & N/A & $\begin{array}{l}\text { Severe } \\
\text { hysterisis }\end{array}$ & $\begin{array}{l}\text { Slight } \\
\text { hysteresis }\end{array}$ & $\begin{array}{l}\text { Slight } \\
\text { hysteresis }\end{array}$ & N/A & N/A \\
\hline $\begin{array}{l}\text { Continued } \\
\text { Evaluation? }\end{array}$ & Yes & No & No & No & No & Yes \\
\hline
\end{tabular}

\section{Forward Work}

Additional testing will be completed on the foil strain gage and StretchSense gages. In addition to further structural tests, packaging, EMI, thermal, and vacuum tests will be completed to further evaluate the gage performance in a space environment. Future full-scale pressurized testing of fabric structures will also be completed using these devices for evaluation. They will be compared directly to the current state-of-the-art photogrammetry systems. With those results, the last project phase is to scale multiple devices into a network to be installed and provide full coverage as a structural health monitoring system for fabric structures. This type of system will ensure that future human rated inflatable habitats will provide safety to their occupants during their operational life and work successfully as designed. 


\section{References}

${ }^{1}$ H. delaFuente, J. L. Raboin, G. R. Spexarth and G. D. Valle, "TransHab: NASA's Large-Scale Inflatable Spacecraft," in AIAA Space Inflatables Forum; Structures, Structural Dynamics, and Materials Conference, Atlanta, Georgia, 2000.

${ }^{2}$ R. Dasgupta, S. Munday and G. D. Valle, "Bigelow Expandable Activity Module (BEAM) - ISS Inflatable Module Technology Demonstration," NASA Johnson Space Center, Houston, Texas, 2014.

${ }^{3}$ D. Litteken, M. Selig, G. Valle and O. Oliveras, "Utilizing Photogrammetry and Strain Gage Measurement to Characterize Pressurization of an Inflatable Module," in AIAA Structures, Structural Dynamics, and Materials Conference, Honolulu, Hawaii, 2012.

${ }^{4}$ G. Swanson, C. Kazemba, K. Johnson, A. Calomino, S. Hughes, A. Cassell and N. Cheatwood, "Overview of the 6 meter HIAD Inflatable Structure and Flexible TPS Static Load Test Series," in International Planetary Probe Workshop, Pasadena, California, 2014.

${ }^{5}$ G. Gioberto and L. Dunne, "Theory and Characterization of a Top-Thread Coverstitch Stretch Sensor," in IEEE International Conference on Systems, Man, and Cybernetics, Seoul, Korea, 2012.

${ }^{6}$ A. Hill, "Low-Weight, Durable, Low-Cost Metal Rubber Sensor System for Ultra-Long-Duration Scientific Balloons," NASA Tech Briefs, pp. 22-23, January 2014.

\section{Acknowledgments}

The author would like to thank the collaborators and student interns that have assisted with the research in this paper, including Cory Simon, Lucy Dunne, Matthew Galeano, Steven Ragland, Steven Torres, Isabelle Edhlund, and Nicholas Schleif. 